\title{
Annexe 3 - Politique d'incitation des pouvoirs régionaux pour le développement du multimédia
}

Contribution de Jean-Marie BASILIEN - 26 octobre 1991

Jean-Marie Basilien

\section{OpenEdition}

\section{Journals}

Édition électronique

URL : http://journals.openedition.org/edc/2735

DOI : $10.4000 /$ edc. 2735

ISSN : 2101-0366

Éditeur

Université Lille-3

Édition imprimée

Date de publication : 1 mai 1993

Pagination : 104

ISSN : 1270-6841

Référence électronique

Jean-Marie Basilien, « Annexe 3 - Politique d'incitation des pouvoirs régionaux pour le développement du multimédia », Études de communication [En ligne], 14 | 1993, mis en ligne le 02 janvier 2012,

consulté le 23 avril 2019. URL : http://journals.openedition.org/edc/2735 ; DOI : 10.4000/edc.2735

Ce document a été généré automatiquement le 23 avril 2019

(C) Tous droits réservés 


\title{
Annexe 3 - Politique d'incitation des pouvoirs régionaux pour le développement du multimédia
}

Contribution de Jean-Marie BASILIEN - 26 octobre 1991

\author{
Jean-Marie Basilien
} quatre ans : lors du premier appel d'offres lancé en 1987-1988, peu de critères pouvaient être utilisés pour sélectionner les projets; et parmi ceux qui ont été retenus, un petit nombre seulement furent menés à bien. En 1990, s'est imposée la nécessité de fixer des "pôles de compétence " régionaux pour la poursuite du programme (priorité aux projets visant la formation générale de base, l'enseignement à distance et l'utilisation de l'image à des fins éducatives) et de mettre en ceuvre les moyens nécessaires pour que les formateurs intègrent l'usage du multimédia dans leur pratique grâce à l'ouverture d'un lieu de ressources (cf. à Lille "Espace Connexion »).

Ce second objectif apparait comme particulièrement important : la situation dans le secteur de la formation professionnelle est en effet encore largement celle d'une majorité de vacataires peu professionnalisés, occupant des emplois précaires; la conséquence directe est que la qualité des formations ne constitue pas un enjeu. A terme, il faudrait aller vers une convention collective instituant un statut national, voire européen, pour des formateurs professionnalisés et performants.

L'intérêt du multimédia, s'il est bien intégré par le formateur dans sa pratique, est qu'il permet à l'apprenant de mieux adhérer à l'acte d'apprentissage. Dire cela, c'est poser la question de la productivité et de la rentabilité de cet acte. Certes, de telles notions sont encore étrangères au secteur de la formation et y provoquent même des réactions hostiles. Il faudrait pourtant définir des indicateurs quantitatifs et qualitatifs, à la fois par le biais de recherches-actions qui permettent de faire l'expérience concrète d'une rentabilité relative, et par une recherche plus théorique. 


\section{AUTEUR}

\section{JEAN-MARIE BASILIEN}

Jean-Marie Basilien, Chargé de mission État-Région pour la formation multimédia à la date de l'intervention ; actuellement Directeur de l'INFAC. 